\title{
Effect of different carboxylic acids as solvent on chitosan fibers production by wet spinning
}

\author{
Rita de Cássia Alves Leal Cruz ${ }^{1}$, Luana Geovanna Marques Diniz ${ }^{1}$, \\ Hugo Miguel Lisboa ${ }^{1}$, Marcus Vinicius Lia Fook ${ }^{1}$
}

I CERTBIO, Department of Materials Engineering, Federal University of Campina Grande,
Zip Code: 58109-970, Campina Grande-PB, Brazil.
e-mail: ritaalvesleal@hotmail.com,luanamdiniz@gmail.com, hugom.lisboa80@gmail.com,marcus.fook@pq.cnpq.br

\begin{abstract}
Over the past decades, chitosan has been extensively investigated and used as a biomaterial due to a set of properties, such as biocompatibility, biodegradability and bioactivity. In the present work to produce the chitosan fibers was used the wet spinning technique and Two parameters, solvent and polymers concentration, were chosen as variables. For polymer concentration two concentrations were applied: $2 \%, 2.5 \%$; and for solvents, three different acids were used: acetic, malic and lactic. Characterizations were carried out, using FTIR, Swelling Degree measurements, SEM and mechanical tests in terms of Traction. From the dimensional analysis of the fiber, different diameters where detected possibly due to steric effects cause by the presence of the acid. Other properties were also affected, revealing that as denser fibers are tend they have higher mechanical properties, and lesser tendency to swell. The fibers showed good potential for application as sutures.
\end{abstract}

Keywords: Biopolymers; Swelling, Mechanical Properties, Medical devices.

\section{INTRODUÇÃO}

The best suture is one that with the least possible inflammatory reaction is able to maintain its tensile strength until the wound healing is complete and be absorbed allowing organ function [1]Technological innovation has provide to surgeons use sutures with characteristics and properties closer to the ideal. On the other hand, for the industrial production control of fibers/wires point of view, by testing and continuous monitoring of the accuracy of the results, it is difficult to achieve, mainly due to high operating costs [2]. Because of the lack of information about such physical properties, the quality of sutures used might be inadequate. The ideal suture should be strong, easy to handle, form firm knots, should promote hemostasis, providing low risk of infection, be comfortable for the patient and form a discrete scar shape. The emergence of new materials for the manufacture of suture wires arouses interest in the possibility of further approximation of what would be the ideal suture [3].

Due to their excellent processing properties and when interacting with the human body, chitosan has been tested for applications in a variety of forms such as hydrogels, fibers, membranes, microspheres, porous and scaffolds [4,5]. Chitin is the second most abundant polysaccharide found in nature and has non-toxic, biodegradable, and antimicrobial characteristics, which are of great interest for packaging purposes. Chitosan is a natural polymer derived by deacetylation of chitin, which is insoluble in usual solvents. However, when the degree of deacetylation of chitin reaches about $50 \%$, it becomes soluble in aqueous acidic media and is called chitosan [6]. Chitosan, are non-toxic, antibacterial, biodegradable and biocompatible biopolymers [7].

Comparative studies between hysterography with sutures of catgut types and chitosan, and found that chitosan wire promoted preventive effect in the formation of post-surgical adhesions in the areas of hysterorrhaphy with increased type III collagen deposition in the process tissue repair and scar giving better quality when compared to catgut[8]. 
A number of methods have been investigated to produce chitosan fibers with good mechanical properties [9-11]. Chitosan is a biopolymer with relevant properties such as biocompatibility and biodegradability in human tissues.

Polymeric fibers used in medicine can be manufactured by three main techniques; melt spinning [12], dry spinning and wet spinning [13]. All of these techniques are based on the polymer extrusion by melt or polymer solution. The process of wet spinning was carried out by several researchers [14-16] allowing to obtain fibers with diameters in the micrometer range (hence being called microfibers) from the previously dissolved chitosan. The theory of wet spinning of chitosan is based on the ability of this material, when in solution, precipitate in bath solutions. The method is based on placing the chitosan solution in a syringe and then extruded it through a needle; it is possible to obtain coagulated and well-oriented fibers, which are subsequently collected in a suitable collector $[9,17]$. The objective of the present work is to study the possible influence of the solvent on the coagulated fiber.

\section{MATERIALS AND METHODS}

\subsection{Chitosan Fiber Preparation}

Solutions were prepared by dissolving Chitosan (Sigma Aldrich, deacetylation degree of 75-85\%, Medium Molecular Weight) at 2.0\%wt and 2.5\%wt concentrations, in three different carboxylic acids (acetic acid, lactic acid and dl-malic acid, Sigma Aldrich, PA) solutions at 1\%wt. Table 1 shows the sample nomenclature identification.

Table 1: Chitosan Solution Samples Identification

\begin{tabular}{l|l|l}
\hline \multicolumn{1}{c|}{ Sample Identification } & \multicolumn{1}{|c}{ Type of Acid } & Chitosan - Concentration (CS) \\
\hline CS2-AA & Acetic acid (AA) & $2 \%$ \\
CS2-AM & DL-Malic acid (AM) & $2 \%$ \\
CS2-AL & Lactic acid (AL) & $2 \%$ \\
CS2.5-AA & Acetic acid (AA) & $2.5 \%$ \\
CS2.5-AM & DL-Malic acid (AM) & $2.5 \%$ \\
CS2.5-AL & Lactic acid (AL) & $2.5 \%$ \\
\hline
\end{tabular}

To obtain chitosan fibers, an infusion pump was used with a syringe and 21 gauge metallic tip. The solution was placed in a syringe and extruded at a ratio of $20 \mathrm{~mL} / \mathrm{h}$. To obtain fibers, a coagulation bath composed by an ethanol / sodium hydroxide 1M (30:70) solution was used. After coagulation, two additional baths were used, a washing bath, consisting of a solution of $50 \%$ ethanol and $50 \%$ distilled water, and a drying bath consisting of $100 \%$ ethanol. After the drying bath, the fibers were placed to dry at room temperature to evaporate the ethanol.

\subsection{Fibers Characterization}

Fibers were characterized by Fourier Transform Infrared spectroscopy with attenuated total reflectance (FTIR-ATR) was performed on a spectrometer model Spectrum 400 FT Mid-IR PerkinElmer with 16 scans with a resolution of $4 \mathrm{~cm}^{-1}$ between $4000-650 \mathrm{~cm}^{-1}$. Swelling degree was performed in PBS (pH 7.4). Samples were cut (dimensions), weighed. The wet weight was measured in $5 \mathrm{~min}$ intervals and each sample was tested in triplicate. SEM micrographs were taken using a TM 1000 HITACHI equipment with voltage of $10 \mathrm{kV}$ and magnification of $20 \mathrm{x}$ to $10,000 \mathrm{x}$. Tensile mechanical tests were performed according to ASTM D2256/2010 [18], using an INSTRON 3366 Universal Machine equipped with a load cell of 500N. 5 samples of each type of fiber with $10 \mathrm{~mm}$ long were pulled using a speed of $120 \mathrm{~mm} / \mathrm{min}$, until break. Fiber diameters were measured with a digital micrometer (Mitutoyo, $0-25 \mathrm{~mm}, 0.001 \mathrm{~mm}$ ) at the beginning of the mechanical test to ensure fibers were completely stretched.

\section{RESULTS AND DISCUSSION}

\subsection{Dimensional Evaluation}

The values of the measured fiber diameters are shown in Table 2.

Analyzing the results shown in Table 2, there are dimensional differences between the different acids used. The fibers produced using acetic acid as solvent, have smaller diameters whereas the lactic acid 
produced fibers with greater diameter. This diameter difference allows us to speculate that the acid molecules are still present in the structure, causing an increase in diameter due to their different molecular volume and steric effects.

Table 2: Chitosan Fiber Diameter and Swelling at Equilibrium

\begin{tabular}{l|l|l}
\hline Sample & Mean Diameter $(\mathbf{m m})$ & Swelling at Equilibrium (\%) \\
\hline CS2-AA & $0.118 \pm 0.011$ & 330 \\
CS2-AM & $0.129 \pm 0.012$ & 520 \\
CS2-AL & $0.148 \pm 0.019$ & 710 \\
CS2.5-AA & $0.149 \pm 0.004$ & 550 \\
CS2.5-AM & $0.132 \pm 0.007$ & 480 \\
CS2.5-AL & $0.149 \pm 0.009$ & 560 \\
\hline
\end{tabular}

It is also noticeable that the concentration of chitosan caused an increase in the diameter of the fibers. This behavior was similar for all fibers produced with three different acids.

\subsection{Swelling Degree}

By analyzing all swelling results, at table 2 , it is noted that all the compositions had high absorption capacity and retention ability of the PBS solution, since the samples absorbed more water than its own weight, as all values are greater than $100 \%$. This measure is a reflection of the water penetration into the fiber, and hence into the interstitial spaces between the polymer chains. Thus a denser fiber will have less space for the penetration of water molecules reducing its swelling capacity. This phenomenon is the basis of the present findings. It is also known that the penetration of water molecules produces a force that is counteracted by the polymer chains, resulting in changes observed over time, until equilibrium is reached. Also by examining the swelling results it is observed that the fibers produced with lactic acid as solvent showed higher water absorption. It is also noted that the wider the fiber is the more water it uptakes, confirming the possibility of void spaces created by steric effects of different acid molecules. This result can be interpreted by the fact that the lactic acid molecule has a hydroxyl group instead of a second carboxylic group in the case of malic acid. Such a molecule could influence the hydrophilicity or simply keep free and more flexible the polymeric chains, allowing greater water uptaking. This effect is also more noticeable for the fiber with $2 \%$ chitosan than for the fibers with $2.5 \%$ perhaps to higher confinement of polymeric chains. The fibers produced by this work showed a much higher swelling capacity than the chitosan fibers produced by TUZLAKOGLU [19], in which the maximum absorption was $120 \%$.

\subsection{FTIR spectra}

FTIR technique was used to investigate the composition of the fibers. Figure 1 shows the vibrational spectra of chitosan and fibers produced with different kinds of acids studied. 


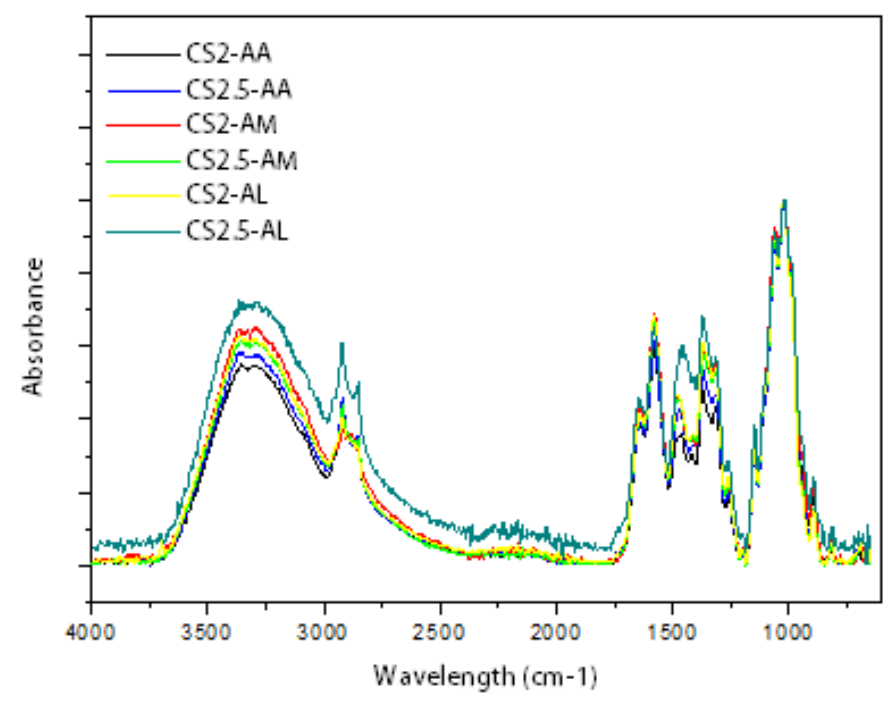

Figure 1: Vibrational Spectra IR of the studied fibers.

Analyzing the spectrum of Figure 1, it is observed an increase in absorption around $3340 \mathrm{~cm}^{-1}$, when using lactic and malic acid, compared to using acetic acid as solvent. This fact can be directly related with the increase of the number of hydroxyl groups present in the chemical structures of those acids. It can also be observed an increase in absorption at around $1650 \mathrm{~cm}^{-1}$, when using malic acid as the solvent, which could be related to the fact that the malic acid is a di-carboxylic acid, which causes an increase in the characteristic absorptions of $\mathrm{C}=\mathrm{O}$ bonds.

The band around $1350 \mathrm{~cm}^{-1}$ is referred to the stretch vibrations of $\mathrm{C}=\mathrm{O}$ present in carboxylic acids, so greater absorption is observed when malic and lactic acid was used. With this result it is confirmed that the carboxylic acid molecules are present in the fibers.

\subsection{Mechanical Tests}

Mechanical properties of fibers produced with chitosan in different solvents are listed in table 4 . As the produced fibers are intended for surgical use, ABNT NBR 13904 [20] was used as reference for evaluation of mechanical properties. Thus, from fibers dimensions, all samples are categorized under the dimensional group of 6-0, which should have a minimum load of $1.77 \mathrm{~N}$. All samples failed to obtain such value, possibly requiring some additive to increase its load capacity.

Table 3: Chitosan Fibers Mechanical Properties

\begin{tabular}{l|l|ll|ll|l|l}
\hline Samples & $\begin{array}{l}\text { ABNT No./ } \\
\text { Load Value (N) }\end{array}$ & $\begin{array}{l}\text { Mean } \\
\text { mum } \\
(\mathbf{N})\end{array}$ & $\begin{array}{r}\text { Maxi- } \\
\text { Load }\end{array}$ & $\begin{array}{l}\text { Mean } \\
\text { mum } \\
(\mathbf{\%})\end{array}$ & $\begin{array}{l}\text { Maxi- } \\
\text { Strain }\end{array}$ & $\begin{array}{l}\text { Mean Maxi- } \\
\text { mum Stress } \\
\text { (MPa) }\end{array}$ & $\begin{array}{l}\text { Mean Young } \\
\text { Modulus } \\
\text { (MPa) }\end{array}$ \\
\hline CS2-AA & & 1.06 & & 103.7 & 106.7 & 721.8 \\
CS2-AM & & 0.98 & & 58.0 & 76.2 & 647.9 \\
CS2-AL & & 1.19 & & 59.0 & & 88.5 & 708.9 \\
CS2.5-AA & $6-0 / 1.77 \mathrm{~N}$ & 1.42 & 1.05 & 45.5 & 86.1 & 651.3 \\
CS2.5-AM & & 1.37 & 119.9 & 80.0 & 608.4 \\
CS2.5-AL & & 57.0 & 72.2 & 551.6 \\
\hline
\end{tabular}

Nevertheless, it is considered that an analysis on mechanical properties should be based on stress values and not on load values, as stress values consider the cross sectional area of the fiber. As it can be observed in table $4,2 \% \mathrm{wt}$ chitosan solution produced fibers with lower maximum load, but higher maximum stress and young modulus, mostly due to the fact that the $2.5 \%$ wt fibers are wider. Due to the higher content 
of polymeric chains with was expected that $2.5 \%$ wt produced fibers with higher mechanical properties. In figure 2, stress-strain curves for some of the samples are shown. Analyzing the type of acid, acetic acid produced fibers with higher load, maximum stress and young modulus, possibly due to less presence of voids, or higher compaction of the fibers, leading to lesser defects.

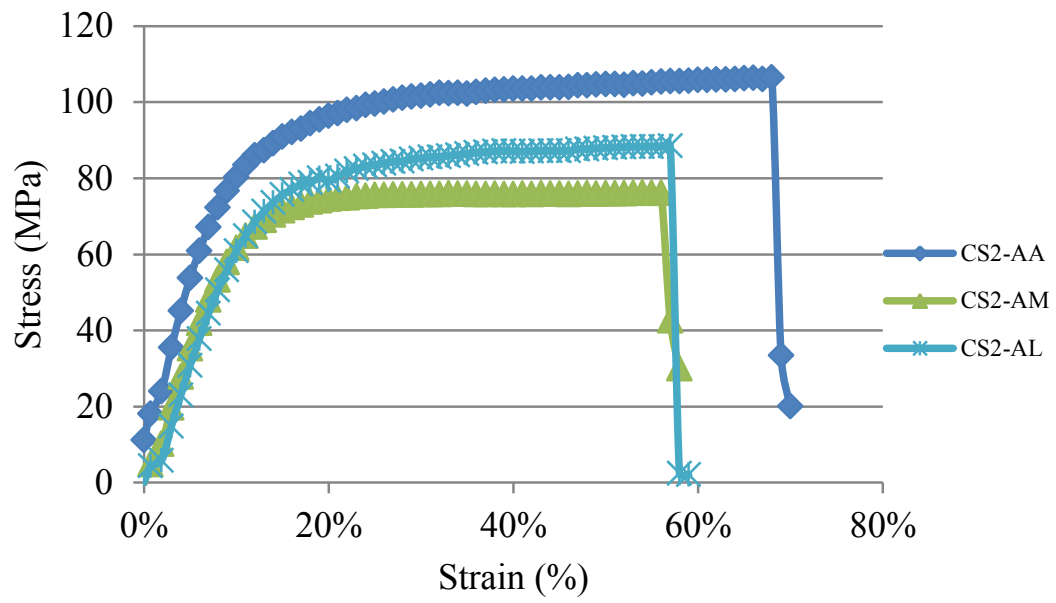

Figure 2: Stress-Strain curves for 2\%wt Chitosan fibers

\subsection{Scanning electron microscopy (SEM)}

SEM micrographs of all fibers are presented in figure 3. From the micrographs is not possible to identify any differences on the surface or structure of the fibers with $2 \%$ wt chitosan.
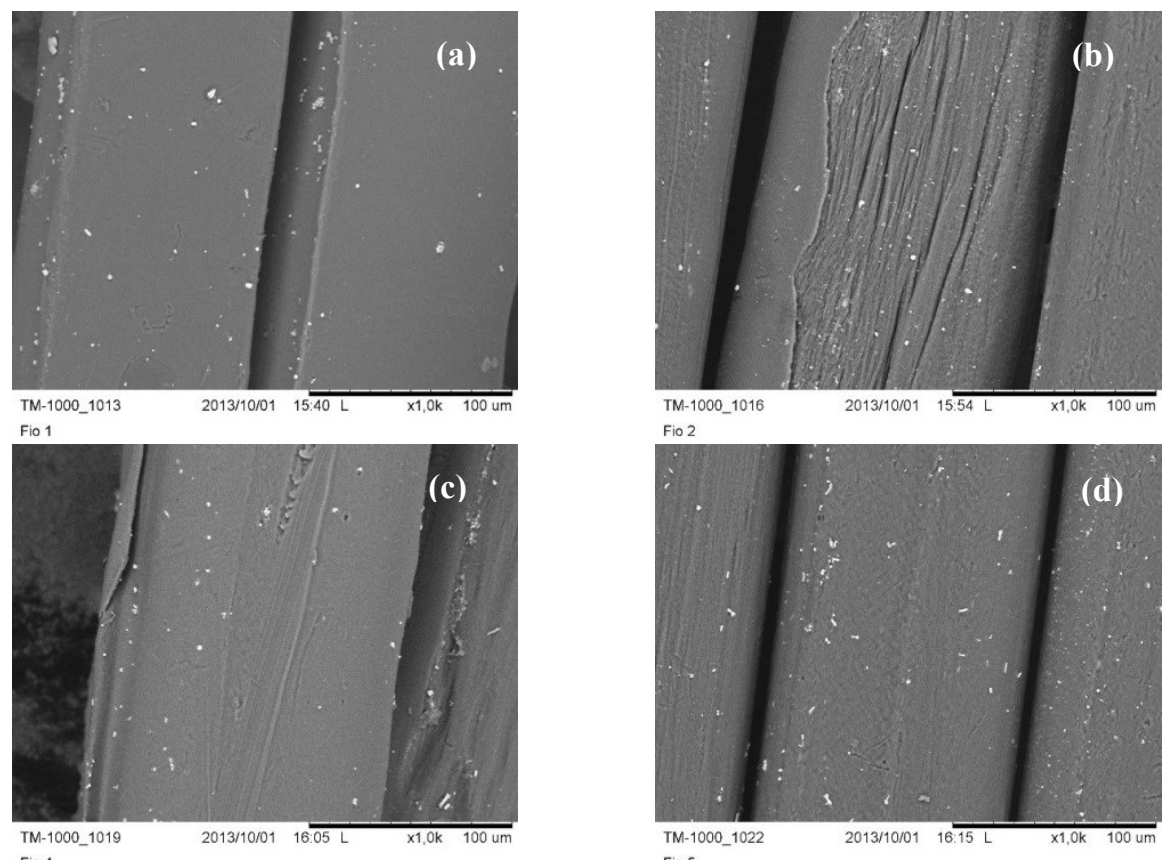

Fio 4 

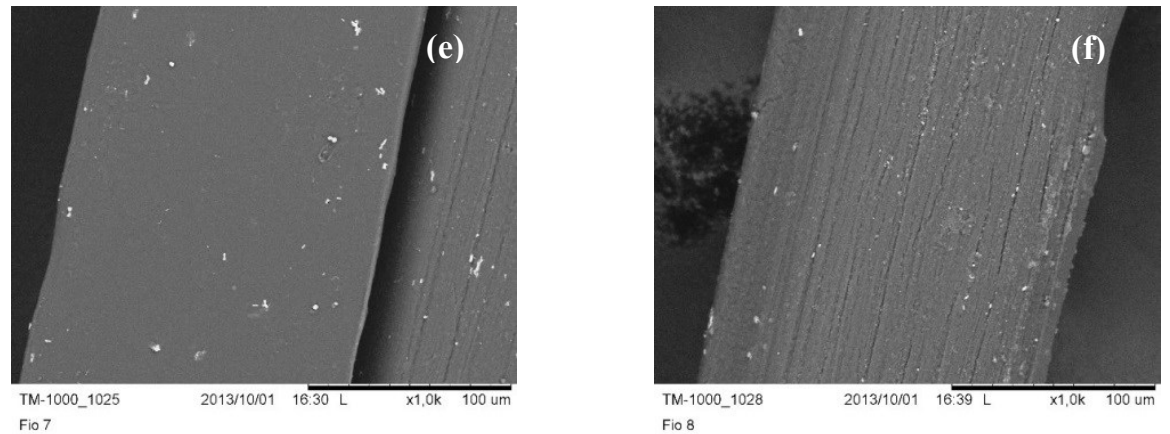

Figure 3: SEM micrographs of chitosan fibers a) CS2-AA b) CS2.5-AA c) CS2-AM d)CS2.5-AM e)CS2-AL f)CS2.5$\mathrm{AL}$

For the fibers extruded from $2.5 \%$ wt chitosan solutions, all acids reveal a similar feature in the surface, resembling an orientation of the fibers in the direction of the extrusion. This possible orientation is due to the physical arrangement of a higher amount of protonated chitosan chains. Small white particles are also visible, possible due to $\mathrm{NaOH}$ contamination from the coagulation bath, and not removed in the washing baths.

\section{CONCLUSIONS}

In the present work it was possible to produce sutures using chitosan fibers dissolved in different solvents by wet spinning. From the results it was possible to identify the presence of acid molecules possibly between chitosan polymeric chains affecting the diameter of the fiber due to steric effects. This affected other properties like the sweeling index and the mechanical tests, as denser fibers tend to have higher mechanical properties, and lesser tendency to swell. With increasing chitosan concentration, the effects are similar. Even though the produced fibers didn't achieve the load capacity required by ABNT NBR 13904, it is considered that they have potential for application as a medical device.

\section{ACKNOWLEDGMENTS}

The authors acknowledged the financial support given by CAPES.

\section{BIBLIOGRAFIA}

[1] FERREIRA, M. L. G. "Estudo comparativo entre os fios de ácido poliglicólico e poliglactina na ileocistoplastia em cães (Canis familiaris)", Revista Brasileira de Ciência Veterinária, v. 12, n. 1, pp. 84-88, 2005.

[2] SARDENBERG, T., MULlER, S. S., SILVARES, P. R. A., et al. "Avaliação das propriedades mecânicas e dimensões de fios de sutura utilizados em cirurgias ortopédicas", Acta Ortop Bras, v. 11, n. 2, pp. 8894, 2003.

[3] BENNETT, R. G. "Selection of wound closure materials", J. Am. Acad. Dermatol, v. 18, n. 4, pp. 619637,1988

[4] MELO, K. G. P. C. Imobilização de pepsina em membranas liofilizadas de quitosana eocarboximetilquitosana, Tese de D. Sc., Faculdade de Ciências Farmacêuticas, Universidade de São Paulo, São Paulo, Brasil, 2009.

[5] NWE, N., FURUIKE, T., TAMURA, H. "The Mechanical and Biological Properties of Chitosan Scaffolds", Materials, v. 2, pp. 374-398, 2009.

[6] RINAUDO, M. "Chitin and chitosan: Properties ad Applications", Progress in Polymer Science. v. 31, pp: $603-632,2006$.

[7] JAYAKUMAR, R. et al. "Novel chitin and chitosan nanofibers in biomedical applications", Biotechnol $A d v$, v. 28, pp. 142-150, 2010.

[8] HUAIZAN, L. N. Comparação entre as histerorrafias com fios de sutura dos tipos categute e quitosana: macrocópica, histoquímica e imunohistoquímica. Tese de MSc., Universidade de Brasília/ Faculdade de Agronomia e Veterinária, Brasília, Brasil, 2013.

[9] KNAUL, J., HOOPER, M., CHANYI, C., et al. "Improvements in the drying process for wet-spun chitosan fibers”, Journal of Applied Polymer Science, v. 69, n. 7, pp. 1435-1444, 1998. 
[10] KNAUL, J. Z., HUDSON, S. M., CREBER, K. A. M. "Improved mechanical properties of chitosan fibers”, J. Appl. Polym. Sci, v. 72, n. 13, pp. 1721-1732, 1999.

[11] ZHENG, H, DU, Y., YU, J, et al. "Preparation and characterization of chitosan/poly(vinyl alcohol) blend fibers". J. Appl. Polym. Sci, v. 80, n. 13, pp. 2558-2565, 2001.

[12] FAMBRI, L., BRAGAGNA, S., MIGLIARESI, C. "Biodegradable fibers of poly- L,DL-lactide 70/30 produced by melt spinning”, Macromol. Symp, v. 234, n. 1, pp. 20-25, 2006.

[13] ELLIS, M. J., CHAUDHURI, J. B. "Poly(lactic-co-glycolic acid) hollow fibre membranes for use as a tissue engineering scaffold”, Biotechnol. And Bioeng, v. 96, n. 1, pp. 177-187, 2007.

[14] PAUL, D. R. "Diffusion during the coagulation step of wet spinning", Journal of Applied Polymer Science, v. 12, pp. 383-402, 1968.

[15] MONCRIEFF, R. Man-made-Fibres. 1 ed., New York, Wiley-interscience, 1970.

[16] ZIABICKI, A., KAWAI, H. High-speed fiber spinning: Science and engineering aspects. 1ed., New York, Wiley-interscience, 1985.

[17] KUMAR, M. N. V. R. "Chitin and chitosan fibres: A review", Bulletin Of Material Science, v. 22, n. 5, pp. 905-915, 1999.

[18] ASTM D 2256. Standard test method for tensile properties of single fibres., Annual Book of ASTM Standards, Engllwood VS \& Brackell, 2010.

[19] TUZLAKOGLU, K. Fiber-Based structures from Natural Origin Pollymers for Tissue Engineering Approches. These D. Sc., Universidade do Minho, Braga, 2007.

[20] ABNT. Associação Brasileira de Normas Técnicas. NBR 13904. Fios para sutura cirúrgica, Rio de Janeiro, 2003. 15p. 